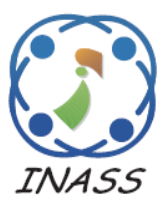

\title{
High Gain Observer-Based Control for Grid-Connected PV System Under Partial Shading Effect
}

\author{
Mohcine Mokhlis ${ }^{1 *}$ \\ Mohammed Ferfra ${ }^{1}$ \\ Rafika El Idrissi ${ }^{1}$ \\ ${ }^{1}$ Department of Electrical Engineering, Mohammadia School of Engineers, \\ Mohammed V University in Rabat, Morocco \\ * Corresponding author’s Email: mohcine1mo@gmail.com
}

\begin{abstract}
This paper proposes the new high-gain observer dedicated to the SEPIC converter and the single-phase inverter. The high-gain observer is designed in order to minimize the number of sensors required, because the use of voltage and current sensors have many disadvantages. In fact, these sensors can obtain a bulky system, also, they are expensive and take up more place. Also, this paper proposes new controller able to locate and track the global maximum power point under the partial shading effect. Actually, when the partial shading occurs, the Power-Voltage curve presents more than one maximum power point, which are divided between the global maximum and the local maximums. The global maximum presents the superior one, while the local maximums present the inferior ones. The classical methods like Perturb and Observe and Incremental Conductance are no longer able to distinguish the global maximum point. So, they cause a high drop of power, which justifies the need of a controller that can solve such problems. Effectively, the proposed controller is designed for this purpose, it consists of an algorithm able to locate the global maximum power point and generate the reference input of corresponding voltage. Also, this controller consists of the sliding mode controller that is able to track the reference input by acting on the SEPIC converter's duty cycle. In addition, the SEPIC converter is connected to the grid through the single-phase inverter. However, to make this connection, it should unify the power factor and synchronize the inverter current with the grid voltage. Effectively, these two tasks are solved by designing the sliding mode controller that acts on the inverter duty-cycle to allow its current to be in the same shape and phase as the grid voltage. Also, the DC bus voltage is regulated by using the PI controller. The overall system is modelled mathematically, tested and validated under Matlab/Simulink environment to show the criteria's performances and efficiency improvement of PV panel by using the proposed Global Maximum Power Point Tracking controller. Moreover, the proposed controller is compared with the hybrid controllers: P\&Osliding mode, IC-sliding mode and PSO-Backstepping controllers. The results illustrate the performance of the proposed controlled to distinguish and track rapidly (about $40 \mathrm{~ms}$ depending on the shading pattern), and accurately the desired global maximum power point.
\end{abstract}

Keywords: Grid connected PV system, High gain observer, Partial shading, SEPIC converter, Sliding mode controller.

\section{Introduction}

Nowadays, the renewable energy is become essential thanks to its many advantages. In fact, this energy is not pollutant and inexhaustible [1], which motivated researchers to develop it and improve its energy production. Between the different existing types of renewable sources, there is the photovoltaic energy. This one is the most used because it can be installed in the roof of houses and close to the customer, which minimizes space, cost and losses of energy due to the transport of electrical energy from the distribution network. Also, the photovoltaic energy sources are easy to install and maintain. However, the power, produced by the photovoltaic modules, is not maximal and depends on the load as well as the external meteorological conditions (irradiation and temperature) $[2,3]$. In order to allow the PV module to produce the maximum of power, it has to connect it to the DC/DC converter or the DC/AC inverter. These converters are able to control the PV module's voltage to be equal to the optimal 
one, which presents the desired voltage that corresponds to the Maximal Power Point (MPP).

Under the uniform conditions of irradiation and temperature, the Power-Voltage (P-V) curve presents a single point of maximum power. So, in order to track the MPP, it must design the Maximum Power Point Tracking (MPPT) techniques. Effectively, several techniques and algorithms have been realized and proposed in the literature. In fact, the Perturb and Observe (P\&O) [4] and Incremental conductance (IC) [5] are the most used because they are easy to implement and don't require high memory space. However, their major drawback is the speed-accuracy dilemma $[6,7]$.

To address this issue, the robust nonlinear controllers are designed. In [8], the hybrid controller composed of the $\mathrm{P} \& \mathrm{O}$ algorithm and the Backstepping controller is proposed, while in [9], the same controller is used by just replacing the $\mathrm{P} \& \mathrm{O}$ algorithm by IC algorithm. Knowing that the hybrid controller can improve the tracking performances, because of the P\&O and IC algorithms which are slightly changed to act on the voltage instead of the duty cycle. However, these controllers can minimize oscillations, but they can not eliminate them definitely.

In [10] and [11], the backstepping and sliding mode controllers (SMC) are designed, respectively. These controllers are robust against the external perturbations, parameter variations and the measurement errors of sensors, also they are accurate and rapid. So, these controllers can improve the PV modules efficiently and can obtain a PV system with good tracking performance criteria.

Under the partial shading effect, the PV panel is subjected to the nonuniform irradiation and temperature, which makes appear several points of maximum power in the power-voltage curve [12]. These points are divided between local and global, and this latter presents the superior maximum. In this case, the MPPT techniques previously discussed cannot distinguish the global maximum, but can just track the MPP very close to $\mathrm{V}_{\mathrm{oc}}$ which can be local or global [14]. Thus, these techniques cause a high drop of power when the partial shading takes place.

The OC\&P algorithm that is proposed in [14], can distinguish and track the global maximum power point GMPP. Here, in this algorithm, the comparison process is launched to look for the GMPP. Then, the $\mathrm{P} \& \mathrm{O}$ algorithm is applied just one time to track this point. Effectively, this algorithm can improve the PV panel efficiency, but cannot obtain a system with good tracking performance criteria, the $\mathrm{P} \& \mathrm{O}$ algorithm used introduces oscillations and obtain a delayed system's response.
In [12], a system composed of two stages is proposed. The first one, called the measurement stage, is controlled in order to sweep the power voltage curve, look for the Global Maximum Power Point (GMPP), and generate the reference of Global Maximal Power (GMP). Then, the second stage, which consists of a boost converter, is controlled in order to track the reference of GMP. In fact, this technique can improve the PV panel efficiency and the performance criteria of the PV system. However, by using the measurement stage, that makes the system expensive and bulky.

The PSO is the most used algorithm under partial shading due to its simplicity and aptitude to distinguish the GMPP [13]. However, this algorithm has a slow convergence in the iterative process [1] and can fall into the local maximum.

This paper proposes a technique able to distinguish and track the global maximum power point rapidly and accurately. Effectively, this one is previously proposed in [1] and improved in this paper, by using the sliding mode controller instead of the backstepping controller, because the sliding mode controller offers robustness against the model uncertainties and a large class of perturbations.

Also, the high gain observer is designed in order to replace some sensors used in the previous work [1]. This observer contributes for reducing space, cost and system complexity. In addition, the proposed controller is compared with some hybrid controllers, the P\&O-sliding mode, IC-sliding mode and PSOBackstepping, to prove its tracking performances and efficiency improvement under uniform and nonuniform meteorological conditions (irradiation and temperature). The PV system is connected to the grid via the $\mathrm{DC} / \mathrm{AC}$ inverter, in this case, the batteries are not needed. However, the DC bus should be regulated, also, the output current has to be synchronous with the grid voltage to obtain the unity power factor. In fact, these two tasks are achieved by using the

Proportional-Integral (PI) controller to regulate the DC bus voltage and using a sliding mode controller to ensure the unity power factor. In addition, the high-gain observer is designed in order to observe and replace the DC/AC inverter output current.

This paper is organized as follows. Section 2 presents the modeling of the PV module and describes the average model of the grid-connected PV system. Section 3 is devoted to the control design as well as the high-gain observer design. The simulation results and conclusion are discussed in sections 4 and 5, respectively. 


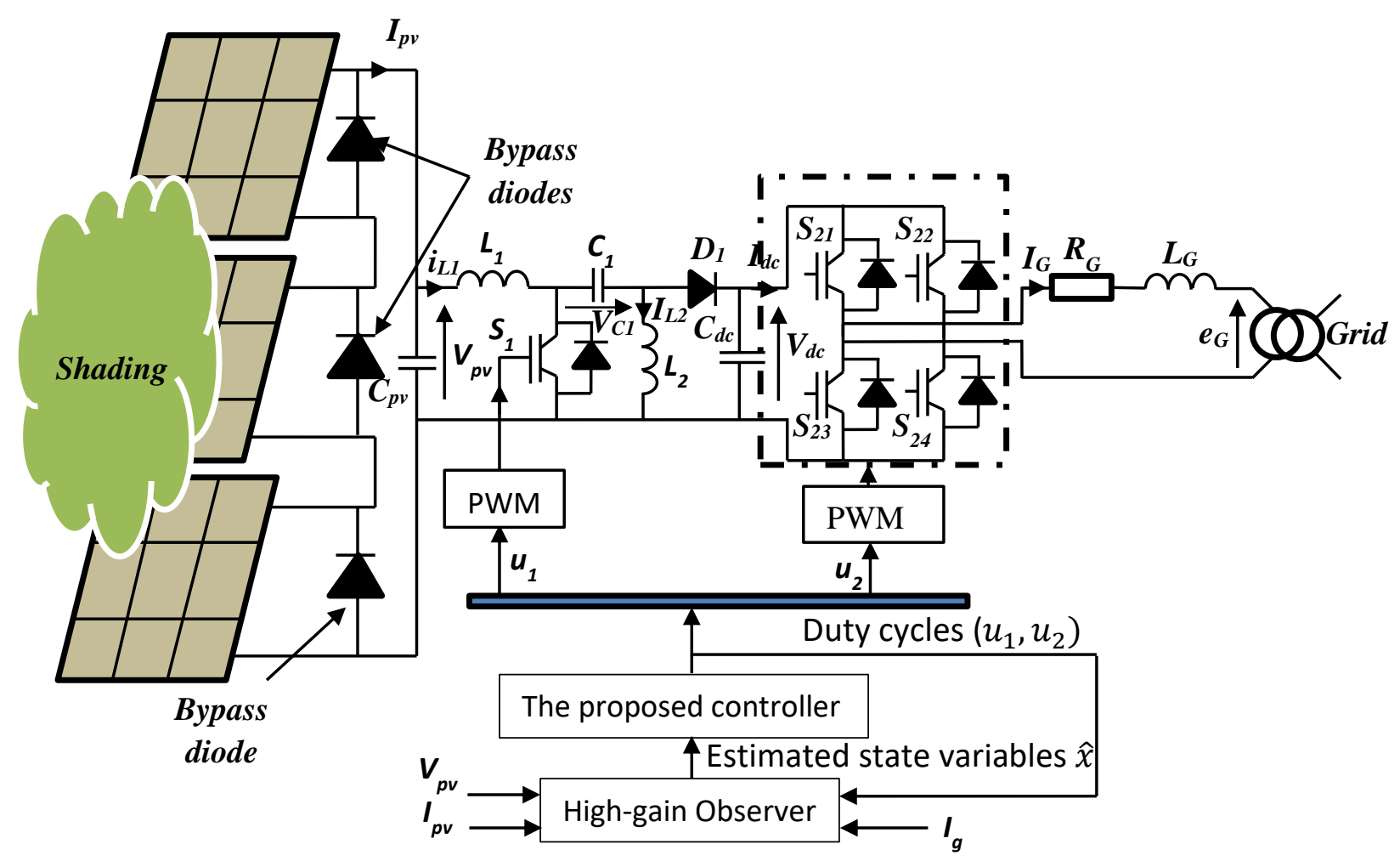

Figure 1. Proposed grid-connected PV system

\section{Nomenclature:}

PV : Photovoltaic.

DC : Direct Current.

$\mathrm{P}-\mathrm{V}$ : Power-Voltage.

$f \quad$ : Grid frequency.

$\mathrm{I}-\mathrm{V}$ : Current-Voltage.

$\sigma_{2}, \sigma_{2}$ : Sliding surfaces.

$\mathrm{AC}$ : Alternating Current.

$\mathrm{P} \& \mathrm{O}$ : Perturb and Observe.

$e_{G \max }:$ Maximal grid voltage.

MPP : Maximal Power Point.

SMC : Sliding mode controller.

IC : Incremental Conductance.

SLG : Sweep, Look and Generate.

PSO : Particle Swarm Optimization.

GMPP : Global Maximum Power Point.

PI : Proportional-Integral controller.

SEPIC : Single Ended Primary Inductor Converter.

\section{PV system modeling}

The grid-connected PV system, proposed in this study, see Fig. 1, consists of a PV panel of three PV modules (Reference: Shell SM55) connected in series, of the SEPIC converter, and a DC/AC inverter connected to the grid. The PV modules are subjected to the partial shading effect. So, the irradiation and temperature, in the overall PV panel, are not uniform, which makes appear several maximum power points divided between local and global, as can be seen in Fig. 2. The SEPIC converter is used because of its ability to reproduce the Power-Voltage curve from $I_{s c}$ (short-circuit current) to $V_{o c}$ (Open-circuit voltage), the noninverted output voltage and currents with fewer oscillations due to the use of two inductors instead of one in the case of the buck-boost converter. The DC/AC inverter is controlled in order to ensure the injection of the PV power to the grid by regulating the DC bus voltage and synchronizing the output current with the grid voltage.

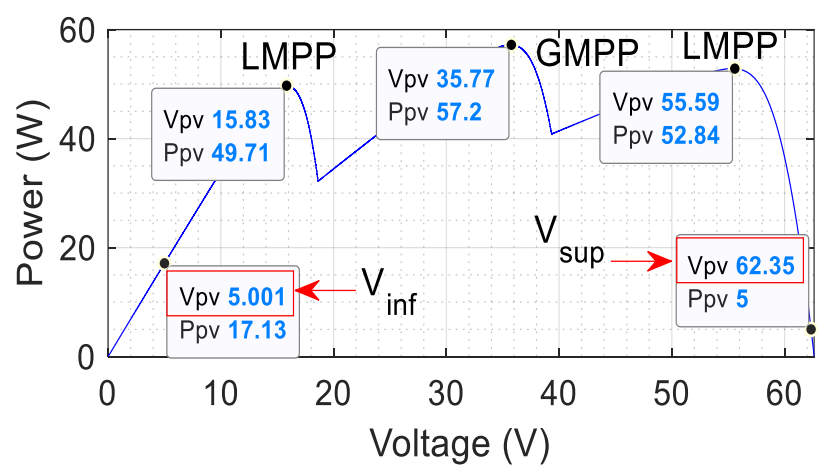

Figure.2 Power-voltage curve of PV panel under partial shading effect 


\subsection{Grid-connected PV system average model}

The average model of the proposed system is expressed as follows [1]:

$$
\left\{\begin{array}{l}
\dot{V}_{p v}=\frac{1}{C_{p v}} I_{p v}-\frac{1}{C_{p v}} I_{L 1} \\
\dot{I}_{L 1}=\frac{1}{L_{1}} V_{p v}-\frac{1}{L_{1}}\left(1-u_{1}\right)\left(V_{C 1}+V_{d c}\right) \\
\dot{V}_{C 1}=\frac{1}{C_{1}}\left(1-u_{1}\right) I_{L 1}-u_{1} \frac{1}{C_{1}} I_{L 2} \\
\dot{I}_{L 2}=u_{1} \frac{1}{L_{2}} V_{C 1}-\left(1-u_{1}\right) \frac{1}{L_{2}} V_{d c} \\
\dot{V}_{d c}=\frac{1}{C_{d c}}\left(I_{L 1}+I_{L 2}\right)\left(1-u_{1}\right)-\left(2 u_{2}-1\right) \frac{I_{G}}{C_{d c}} \\
\dot{I}_{G}=\left(-R_{G} I_{G}-e_{G}+\left(2 u_{2}-1\right) V_{d c}\right) / L_{G}
\end{array}\right.
$$

where:

$$
\begin{array}{ll}
e_{G} & : \text { Grid voltage. } \\
I_{G} & : \text { Current of grid. } \\
V_{d c} & : \text { DC bus voltage. } \\
C_{d c} & \text { : DC bus capacitor. } \\
V_{p v} & : \text { PV panel voltage. } \\
I_{p v} & : \text { PV panel current. } \\
u_{1} & : \text { SEPIC converter's duty cycle. } \\
u_{2} & : \text { DC/AC inverter's duty cycle. }
\end{array}
$$$$
V_{C l} \quad \text { : Voltage at the capacitor } C_{I} \text { terminals. }
$$$$
C_{p v} \quad \text { : Input capacitor of the SEPIC converter. }
$$$$
L_{1}, L_{2} \quad \text { : SEPIC converter Inductors' inductances. }
$$$$
I_{L 1}, I_{L 2}: \text { Inductor currents of the SEPIC converter. }
$$$$
L_{G}, R_{G}: \text { Grid filter inductor and series resistance. }
$$

\subsection{Modeling of PV module}

The photovoltaic module, composed of $N_{s}$ singlediode cells in series connection, is expressed by the following equation [15]:

$$
I_{p v}=I_{p h}-I_{s}\left[\exp \left(q \frac{F_{1}}{\alpha N_{s} K T}\right)-1\right]-\frac{F_{1}}{R_{s h}}
$$

where

Table 1. Specifications of Shell SM55 PV modules

\begin{tabular}{|l|c|}
\hline \multicolumn{1}{|c|}{ Parameters } & Values \\
\hline Maximum power $P_{\max }$ & $55 \mathrm{~W}$ \\
\hline Optimal voltage $V_{o p t}$ & $17.4 \mathrm{~V}$ \\
\hline Optimal current $I_{o p t}$ & $3.15 \mathrm{~A}$ \\
\hline Short-circuit current $I_{s c}$ & $3.45 \mathrm{~A}$ \\
\hline Open-circuit voltage $V_{o c}$ & $21.7 \mathrm{~V}$ \\
\hline Temperature coefficient $K_{i}$ of $I_{s c}$ & $1.4 \times 10^{-3} \mathrm{~A} /{ }^{\circ} \mathrm{C}$ \\
\hline Number of cells $N_{s}$ & 36 \\
\hline
\end{tabular}

$$
\begin{gathered}
F_{1}=V_{p v}+I_{p v} R_{s} \\
I_{p h}=\left[I_{p h 0}+K_{i}\left(T-T_{s t c}\right)\right] \frac{G}{G_{s t c}}
\end{gathered}
$$

and

$$
I_{s}=I_{s 0}\left(\frac{T}{T_{s t c}}\right)^{3} \exp \left(q \frac{E_{G}}{\alpha K}\left(\frac{1}{T_{s t c}}-\frac{1}{T}\right)\right)
$$

with:

K : Boltzmann constant.

$\alpha \quad:$ The ideality coefficient.

$N_{s} \quad$ : Number of PV module cells.

$R_{s}, R_{s h} \quad$ : The series and shunt resistors.

$K_{i} \quad$ : The temperature coefficient of $I_{s c}$.

$G, T$ : Ambient irradiations and temperatures.

$G_{s t c}, T_{s t c}$ : Standard irradiations and temperatures.

$q \quad$ : Electron charge $\left(1.60217646 e^{-19} C\right)[22]$.

$E_{G} \quad:$ The band-gap energy that is equal 1.2 for the polycrystalline silicon solar cells [1].

$I_{s}, I_{p h}$ : The saturation and photo-current measured under ambient conditions.

$I_{s 0}, I_{p h 0}:$ The saturation and photo-current measured under standard conditions.

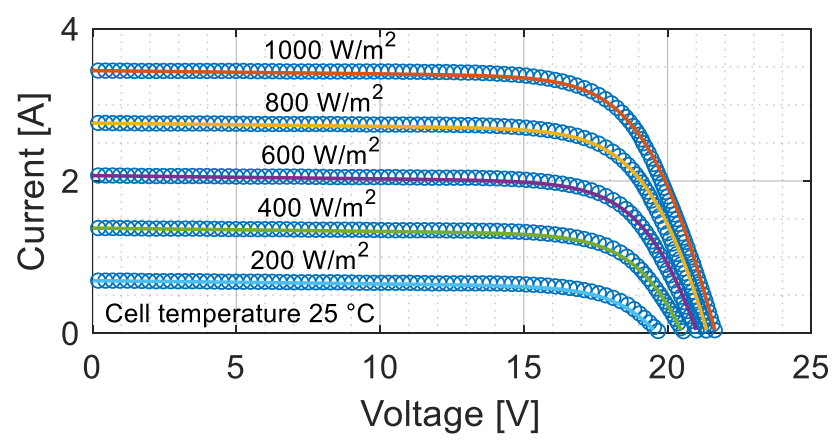

(a)

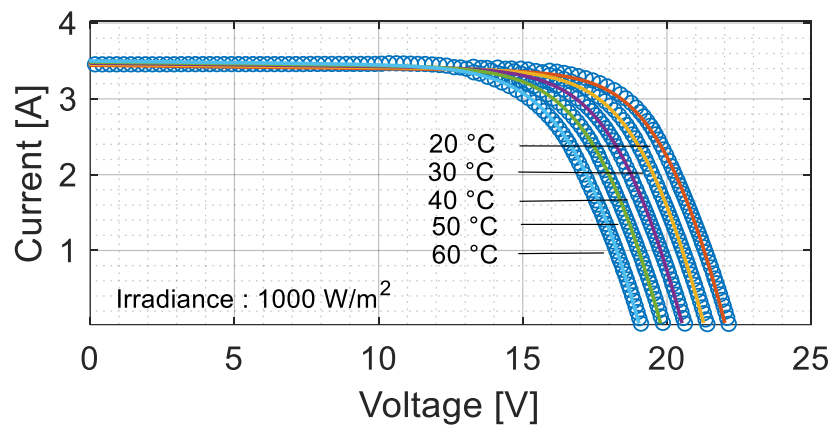

(b)

Figure. 3 The I-V curves of the mathematical model and the experimental data under (a) a temperature of $25^{\circ} \mathrm{C}$ and changed irradiation, (b) an irradiation of $1000 \mathrm{~W} / \mathrm{m}^{2}$ and changed temperature 
In fact, $R_{s}, R_{s h}, I_{p h 0}, I_{s 0}$ and $\alpha$ are the unknown parameters those must be defined in order to obtain a mathematical model of PV module that can mimic the real one. Effectively, this is realized based on the following equations as given in [1]:

$$
\left\{\begin{array}{c}
I_{p h 0}=\left(\frac{R_{s}+R_{s h}}{R_{s h}}\right) I_{s c} \\
I_{s 0}=\frac{I_{s c}}{\exp \left(\frac{V_{o c}}{V_{t}}\right)-1} \\
\exp \left(\frac{V_{o p t}+R_{s} I_{o p t}-V_{o c}}{V_{t}}\right)=\frac{A}{B-C} \\
R_{s h}=\frac{D\left(V_{o p t}-R_{s}\left(I_{s c}-I_{o p t}\right)-V_{t}\right)}{D\left(I_{s c}-I_{o p t}\right)-V_{t} I_{o p t}}
\end{array}\right.
$$

where

$$
\left\{\begin{array}{l}
V_{t}=\frac{\alpha K N_{s} T_{s t c}}{q} \\
A=V_{o p t} V_{t}\left(2 I_{o p t}-I_{s c}\right) \\
B=D\left(V_{o p t} I_{s c}+V_{o c}\left(I_{o p t}-I_{s c}\right)\right) \\
C=V_{t}\left(V_{o p t} I_{s c}-V_{o c} I_{o p t}\right) \\
D=\left(V_{o p t}-I_{o p t} R_{s}\right)
\end{array}\right.
$$

with:

$$
\begin{array}{ll}
I_{o p t} & : \text { Optimal current. } \\
V_{\text {opt }} & : \text { Optimal voltage. } \\
I_{s c} & : \text { Short-circuit current. } \\
V_{o c} & : \text { Open-circuit voltage. } \\
V_{t} & : \text { Thermal voltage. }
\end{array}
$$$$
A, B, C, D \text { : Supposed parameters. }
$$

These parameters are given in the datasheet, and illustrated in Table 1 . The ideality coefficient $\alpha$ is considered equal 1.3 [1], this value is adjusted until the Current-Voltage (I-V) curve of the mathematical model fits the I-V curve given in the datasheet, see Fig. 3-a and Fig. 3-b.

After replacing parameters, given in Table 1, in Eqs. (6) and (7), the unknown parameters are calculated:

$$
\left\{\begin{array}{l}
\alpha=1.3 \\
R_{s}=0.3355 \Omega \\
R_{s h}=235.9 \Omega \\
I_{p h 0}=3.445 A \\
I_{s 0}=5.013 \times 10^{-8} \mathrm{~A}
\end{array}\right.
$$

\section{Control design}

In order to track the global maximum power point, the algorithm called SLG is proposed, see Fig. 4. This one sweeps the power-voltage curve, looks for the GMPP and generates the corresponding optimal voltage.

During the first time interval, see Fig. 5, the SLG algorithm starts generating a signal reference that varies from 0 to $V_{o c}$ by the fixed step step size $V_{i}$ $\left(V_{i}=0.2 \mathrm{~V}\right)$. Then, the sliding mode controller is designed and applied in order to track this reference voltage by adjusting the duty cycle of the SEPIC converter. Which allows to this converter to reproduce the power-voltage curve at terminals of the PV module. Also, during this time interval, the algorithm scans the power-voltage curve reproduced, looks for the GMPP by comparing the current power with the previous one, and stores the maximal power and its corresponding voltage. During the second time interval, the algorithm generates the reference of optimal voltage that is found during the first time interval. Effectively, this voltage corresponds to the GMPP. The sliding mode controller is applied again in order to track the voltage reference. Which allows to the SEPIC converter to reproduce the global maximal power at the terminals of the PV panel.

All th process, that is discussed previously, repeats any time when the change of irradiation and/or temperature is detected. The detection can make when one of the following conditions is true.

$$
\begin{gathered}
\left\{\begin{array}{c}
V_{P V}-V_{o p t} \leq-\Delta V \\
P_{P V}-P_{\max } \leq-\Delta P
\end{array}\right. \\
P_{P V}-P_{\text {max }} \geq \Delta P
\end{gathered}
$$

with $\Delta V$ and $\Delta P$ are the detection thresholds.

In fact, it is not necessary to scan all the Powervoltage-curve to find the desired maximum point of power. For this reason, the points of voltage very close to $I_{s c}$ and $V_{o c}$ are not scanned. That is made by imposing the sliding mode controller to track the reference voltage, generated during the first time interval, except to not exceed $V_{\text {sup }}$ and do not get off of $V_{\text {inf }}$, see Fig. 2 and Fig. 5. Here, $V_{\text {inf }}$ is supposed equal to $5 \mathrm{~V}$ as a minimal voltage. While $V_{\text {sup }}$ is the maximal voltage, this one can be found when the following condition is true:

$$
\left\{\begin{array}{l}
V_{p v} \geq V_{c} \\
P_{p v} \leq P_{c}
\end{array}\right.
$$




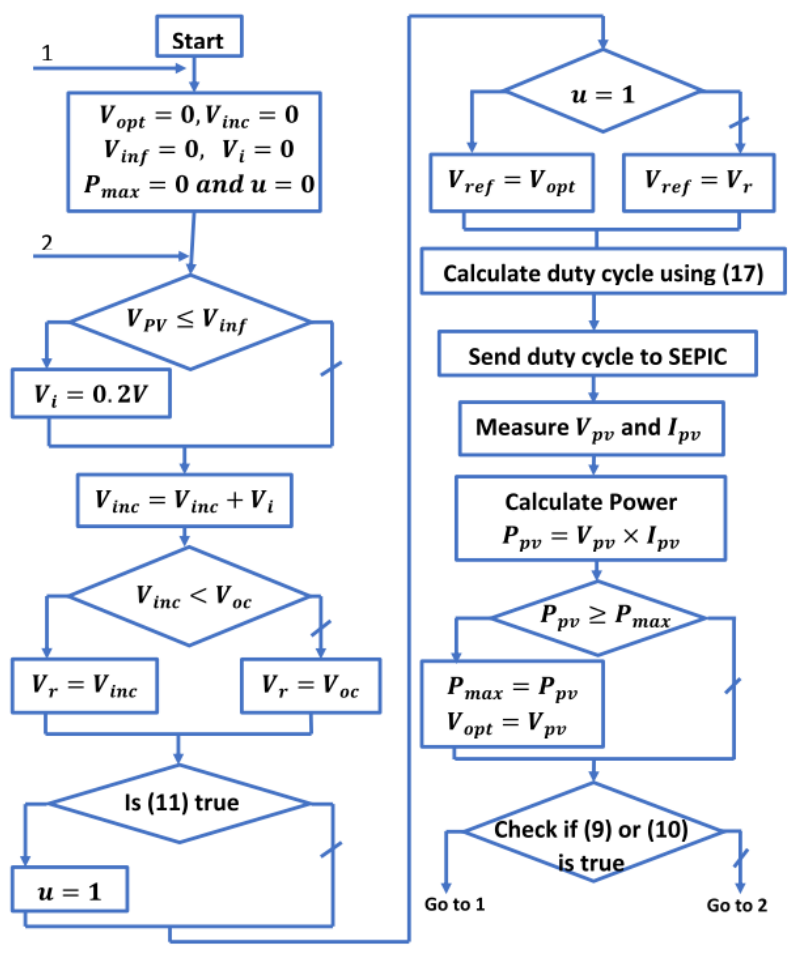

Figure.4 Flowchart of the proposed SLG-SMC algorithm with

$P_{p v}: \mathrm{PV}$ power.

$V_{c}$ : Constant variable supposed equal $17 \mathrm{~V}$.

$P_{c}$ : Constant variable supposed equal $5 \mathrm{~W}$.

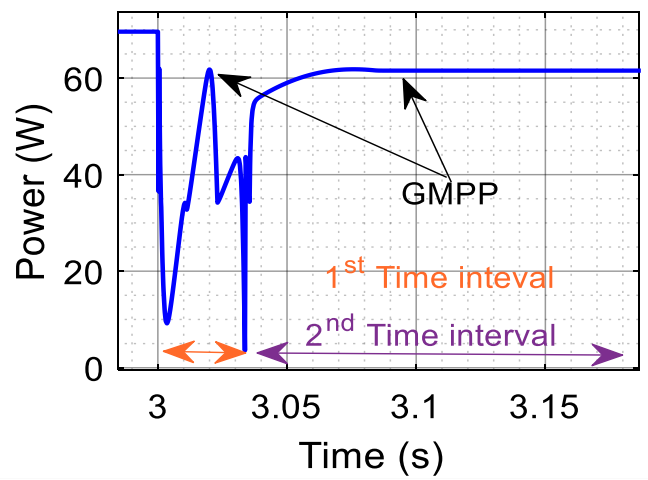

(a)

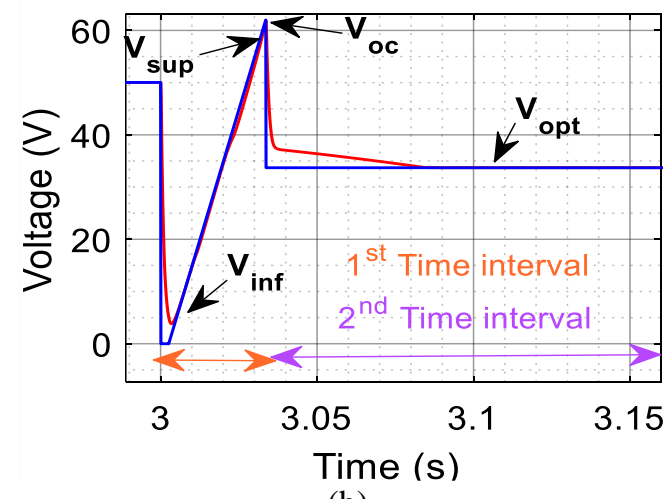

(b)

Figure.5 Power and voltage of the PV panel

\subsection{Sliding mode controller design}

The sliding mode command is a nonlinear controller that is able to control the nonlinear systems to pursue any reference signal. The SMC controller is designed in order to allow the controlled output $y_{1}=$ $V_{p v}$ to track the desired output $y_{\text {Iref }}=V_{\text {ref. }}$.

The step design of SMC are as follows:

Firstly, it must define the tracking error, this one is expressed as follows:

$$
\varepsilon_{1}=y_{1}-y_{1 r e f}=V_{p v}-V_{r e f}
$$

Then, the sliding surface is defined:

$$
\sigma_{1}=\left(\frac{d y_{1}}{d t}+\lambda_{1}\right)^{r_{1}-1} \varepsilon_{1}
$$

with

$\lambda_{1}:$ Positive constant.

$r_{1}$ : The relative degree, of the output $y_{1}$, is equal 2. This degree is found by deriving the output $y_{l}$ as a function of time until the control input $u_{1}$ appears [11].

Thus, the sliding surface will be as follows:

$$
\sigma_{1}=\left(\frac{d y_{1}}{d t}+\lambda_{1}\right)^{2-1} \varepsilon_{1}=\dot{\varepsilon}_{1}+\lambda_{1} \varepsilon_{1}
$$

Thus:

$$
\sigma_{1}=\dot{V}_{P V}-\dot{V}_{\text {ref }}+\lambda_{1} \varepsilon_{1}
$$

Replacing Eq. (1) in Eq. (15):

$$
\sigma_{1}=\frac{1}{C_{p v}}\left(I_{p v}-I_{L 1}\right)-\dot{V}_{r e f}+\lambda_{1} \varepsilon_{1}
$$

The time derivative of Eq. (16) is:

$$
\begin{gathered}
\dot{\sigma}_{1}=\frac{1}{C_{p v}}\left(\dot{I}_{p v}-\dot{I}_{L 1}\right)-\ddot{V}_{r e f}+\lambda_{1} \dot{\varepsilon}_{1} \\
\dot{\sigma}_{1}=\frac{1}{C_{p v}}\left(F_{2} \dot{V}_{p v}-\dot{I}_{L 1}\right)-\ddot{V}_{r e f}+\lambda_{1} \dot{\varepsilon}_{1}
\end{gathered}
$$

with

$$
F_{2}=\frac{d I_{p v}}{d V_{p v}}=-I_{s} \frac{q}{\alpha N_{s} K T} \exp \left(q \frac{V_{p v}}{A N_{s} K T}\right)
$$




$$
\dot{I}_{p v}=\frac{d V_{p v}}{d t}=\frac{d I_{p v}}{d V_{p v}} \frac{d V_{p v}}{d t}=F_{2} \dot{V}_{p v}
$$

$\mathrm{F}_{2}$ is obtained considering that the resistance $\mathrm{R}_{\mathrm{s}}$ negligible and $\mathrm{R}_{\mathrm{sh}}$ infinite.

The sliding mode exists if the attractiveness condition is true:

$$
\dot{V}_{1}=\dot{\sigma}_{1} \sigma_{1}<0
$$

Therefore, the Lyapunov stability can be guaranteed if $\dot{V}_{1}=-K_{1}\left|\sigma_{1}\right|$ in the closed loop. Which can be done if:

$$
\dot{\sigma}_{1}=-K_{1} \operatorname{sign}\left(\sigma_{1}\right)
$$

where

$K_{l}$ : positive constant.

sign : Signum function.

So, replacing Eq. (17) in Eq. (20), the input control u1 can be found:

$u_{1}=\left[F_{3}+\frac{1}{C_{p v}}\left(F_{2} \dot{V}_{p v}-\frac{1}{L_{1}} V_{p v}\right)+\lambda \dot{V}_{p v}\right] Z+1$

Considering that:

$$
\left\{\begin{array}{l}
F_{3}=K_{1} \operatorname{sing}\left(\sigma_{1}\right) \\
Z=\frac{C_{p v} L_{1}}{V c_{1}+V_{d c}}
\end{array}\right.
$$

\subsection{Grid Current control}

In order to obtain a unity power factor and to inject the sinusoidal current to the grid, this current should have the same shape and phase as the grid voltage. To achieve this, the sliding mode controller is designed. This one forces the output current to pursue a reference signal, which is the multiplication of the network voltage by a positive parameter generated by the PI controller $\left(I_{\text {Gref }}=\beta \cdot e_{G}=\right.$ $\beta E \sqrt{2} \sin (2 \pi f)$ ), which is used in order to regulate the DC bus voltage to track the desired reference voltage.

\subsubsection{Sliding mode controller design}

The steps design of the sliding mode controller are as follows:
Define the tracking error $\varepsilon_{2}$ :

$$
\varepsilon_{2}=y_{2}-y_{2 r e f}=I_{G}-I_{\text {Gref }}
$$

The sliding surface is expressed as follows:

$$
\sigma_{2}=\left(\frac{d y_{2}}{d t}+\lambda_{2}\right)^{r_{2}-1} \varepsilon_{2}
$$

with

$\lambda_{2}:$ Positive constant.

$r_{2}$ : The relative degree of the output $y_{2}$, it is equal 1 .

Thus, the sliding surface will be as follows:

$$
\sigma_{2}=\left(\frac{d y_{2}}{d t}+\lambda_{2}\right)^{1-1} \varepsilon_{2}=\varepsilon_{2}
$$

The time derivative of Eq. (21) gives:

$$
\dot{\sigma}_{2}=\dot{\varepsilon}_{2}
$$

Knowing that:

$$
\dot{\varepsilon}_{2}=\dot{y}_{2}-\dot{y}_{2 r e f}=\dot{I}_{G}-\dot{I}_{\text {Gref }}
$$

So, replacing Eq. (1) in Eq. (27), $\dot{\varepsilon}_{2}$ will be:

$$
\dot{\varepsilon}_{2}=\frac{\left(-R_{G} I_{G}-e_{G}+\left(2 u_{2}-1\right) V_{d c}\right)}{L_{G}}-\dot{I}_{G r e f}
$$

The sliding mode exists if the following attractiveness condition is true:

$$
\dot{V}_{2}=\dot{\sigma}_{2} \sigma_{2}<0
$$

The Lyapunov stability can be guaranteed if $\dot{V}_{2}=$ $-K_{2}\left|\sigma_{2}\right|$ in the closed loop. Which can be done if:

$$
\dot{\sigma}_{2}=-K_{2} \operatorname{sign}\left(\sigma_{2}\right)
$$

With

$K_{2}$ : positive constant.

sign : Signum function.

So, replacing Eq. (28) in Eq. (30), the input control $\mathrm{u}_{2}$ can be found: 
$u_{2}=\left[R_{G} I_{G}+e_{G}+V_{d c}+\left(\dot{\varepsilon}_{2}+\frac{d I_{\text {gref }}}{d t}\right) L_{g}\right] \frac{1}{2 V_{d}}$

\subsubsection{Proportional-integral controller}

The aim behind using this controller is to generate the ratio $\beta$ that allow the $V_{d c}$ to pursue the $V_{d c r e f}$, the block diagram of this PI controller block is illustrated in Fig. 6.

The PI controller is defined by:

$$
\beta(t)=K_{p} \varepsilon_{d c}(t)+K_{i} \int \varepsilon_{d c}(t) d t
$$

with

$\mathrm{K}_{\mathrm{i}}, \mathrm{K}_{\mathrm{p}}$ : The positive regulation parameters.

$\varepsilon_{d c}$ : Error between $V_{d c}$ and $V_{d c r e f}$, can be expressed as follows:

$$
\varepsilon_{d c}(t)=V_{d c}-V_{d c r e f}
$$

\subsection{Grid Current control}

The high-gain observer is proposed in order to replace some sensors used, which minimizes the corresponding electrical perturbations, cost and space. In fact, this observer needs only the PV current and voltage to estimate $V_{C 1}, V_{d c}$ and $I_{G}$.

The dynamical model of the connected grid PV system can be expressed under the following canonical form:

$$
\left\{\begin{array}{l}
\dot{x}_{1}=a_{1}(u) x_{2}+\varphi_{1}\left(x_{1}, u\right) \\
\dot{x}_{2}=a_{2}(u) x_{3}+\varphi_{2}\left(x_{1}, x_{2}, u\right) \\
\dot{x}_{3}=a_{3}(u) x_{4}+\varphi_{3}\left(x_{1}, x_{2}, x_{3}, u\right) \\
\dot{x}_{4}=a_{4}(u) x_{4}+\varphi_{4}\left(x_{1}, x_{2}, x_{3}, x_{4}, u\right) \\
\dot{x}_{5}=a_{5}(u) x_{5}+\varphi_{5}\left(x_{1}, x_{2}, x_{3}, x_{4}, x_{5}, u\right) \\
\dot{x}_{6}=\varphi_{6}\left(x_{1}, x_{2}, x_{3}, x_{4}, x_{5}, x_{6}, u\right) \\
y=x_{1}
\end{array}\right.
$$

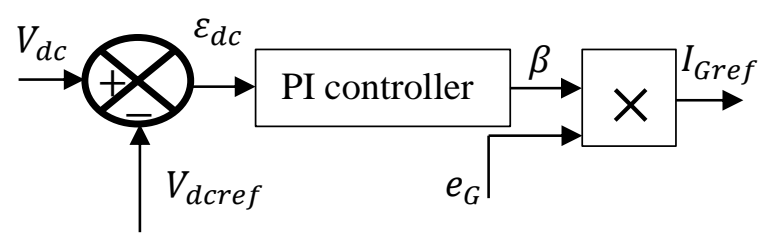

Figure.6 Regulation block of the DC voltage
Using Eq. (1) and Eq. (34), it can be concluded that:

$$
\begin{aligned}
& a_{1}(u)=-\frac{1}{C_{p v}} \\
& a_{2}(u)=-\frac{1}{L_{1}}\left(1-u_{1}\right) \\
& a_{3}(u)=-u_{1} \frac{1}{C_{1}} \\
& a_{4}(u)=-\left(1-u_{1}\right) \frac{1}{L_{2}} \\
& a_{5}(u)=-\left(2 u_{2}-1\right) \frac{1}{C_{d c}}
\end{aligned}
$$

And:

$\varphi_{1}(x, u)=\frac{1}{C_{p v}} I_{p v}$

$\varphi_{2}(x, u)=\frac{1}{L_{1}} V_{p v}-\frac{1}{L_{1}}\left(1-u_{1}\right) V_{d c}$

$\varphi_{3}(x, u)=\frac{1}{C_{1}}\left(1-u_{1}\right) I_{L 1}$

$\varphi_{4}(x, u)=u_{1} \frac{1}{L_{2}} V_{C 1}$

$\varphi_{5}(x, u)=\frac{1}{C_{d c}}\left(I_{L 1}+I_{L 2}\right)\left(1-u_{1}\right)$

$\varphi_{6}(x, u)=\left(-R_{G} I_{G}-e_{G}+\left(2 u_{2}-1\right) V_{d c}\right) / L_{G}$

Thus, the following condensed form can be obtained:

$$
\left\{\begin{array}{c}
\dot{x}=A(u) x+\varphi(x, u) \\
y=C x
\end{array}\right.
$$

where:

$$
\begin{aligned}
& A(u)=\left[\begin{array}{cccccc}
0 & a_{1}(u) & 0 & 0 & 0 & 0 \\
0 & 0 & a_{2}(u) & 0 & 0 & 0 \\
0 & 0 & 0 & a_{3}(u) & 0 & 0 \\
0 & 0 & 0 & 0 & a_{4}(u) & 0 \\
0 & 0 & 0 & 0 & 0 & a_{5}(u) \\
0 & 0 & 0 & 0 & 0 & 0
\end{array}\right] \\
& C=\left[\begin{array}{cccccc}
1 & 0 & 0 & 0 & 0 & 0
\end{array}\right] \\
& \varphi=\left[\begin{array}{llllll}
\varphi_{1} & \varphi_{2} & \varphi_{3} & \varphi_{4} & \varphi_{5} & \varphi_{6}
\end{array}\right]^{T}
\end{aligned}
$$

Knowing that $\varphi(x, u)$ is the locally Lipchitz nonlinear function.

Thus, the candidate observer of the Grid connected PV system can be described by the following dynamical system:

$$
\left\{\begin{array}{c}
\dot{\hat{x}}=A(u) \hat{x}+\varphi(\hat{x}, u)-S^{-1} C^{T}(C \hat{x}-y) \\
\dot{S}=-\theta S-A^{T}(u)-S A(u)+C^{T} C \\
\hat{y}=C \hat{x}
\end{array}\right.
$$



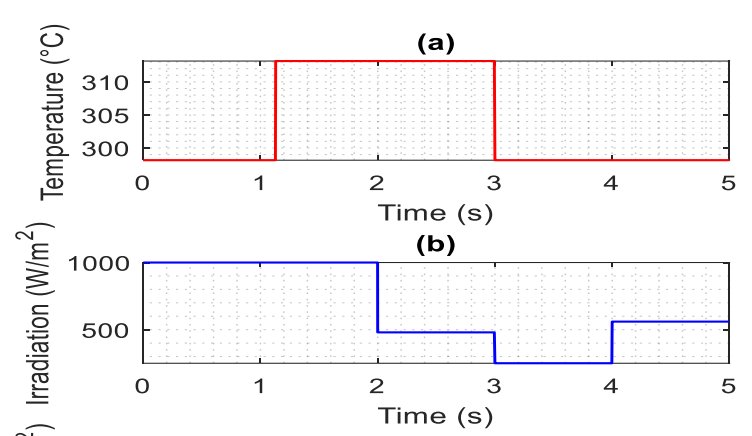

(c)

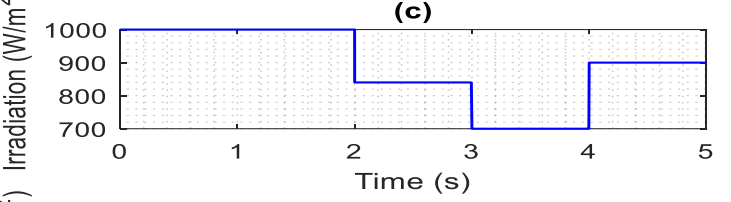

(d)

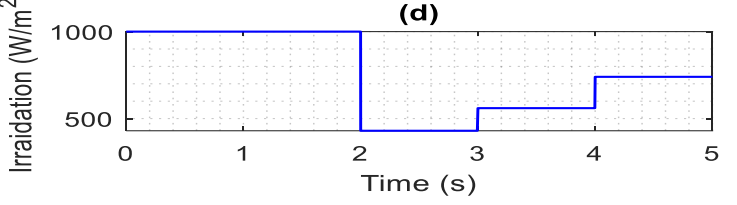

Figure.7 Meteorological conditions in the PV panel

where $\mathrm{y}$ and $\mathrm{u}$ are the measured output and input control, respectively. $\hat{x}$ is the estimated state. While $\mathrm{S}$ is the differential Lyapunov equation solution that is presented by the symmetric positive matrix. $\theta$ is the observer adjustment positive parameter.

\section{Simulations and results discussion}

In order to validate the proposed controller as well as the system, simulations are made under MATLAB/ Simulink environment. As can be seen in Fig. 7, the photovoltaic panel is supposed subjected to the uniform meteorological conditions during the first-time interval that is $[0,2 s]$. Then, between $2 s$ and $5 s$ second the PV panel is supposed subjected to the non-uniform meteorological conditions which means that the partial shading takes place during this period of time.

Whenever the meteorological conditions change, the voltage reference varies rapidly from 0 to $V_{o c}$, then returns the optimal voltage $V_{o p t}$, see Fig. 8. During this time, the sliding mode controller regulates the duty cycle of the SEPIC converter in order to track this reference of voltage, which consequently allows this converter to reproduce the power-voltage curve at the terminals of the PV panel and to return the GMPP, as can be seen in Fig. 9 (a). So, this process repeats any time where the change of irradiation and/or temperature is detected. Therefore, the controller works properly with good tracking performances (rapidity and accuracy), also it can distinguish the GMPP and detect the meteorological conditions change.
The input control that is the duty cycle of the SEPIC converter is depicted in Fig. 10.

To prove the proposed controller efficiency improvement under the partial shading effect, this controller is compared with the Sliding mode controller combined with the $\mathrm{P} \& \mathrm{O}$ and IC algorithms, respectively, see Fig. 9(b). So, as can be seen in this figure, at $t=2 s$, where the partial shading takes place, the P\&O-sliding mode and IC-Sliding mode controllers are able to track the global maximum point of power, while at $t=3 \mathrm{~s}$, these controllers fall at the local maximum point and make the high drop of the power. It can be concluded that these controllers cannot distinguish the global maximum point, but they can just track the maximum very close to the open-circuit voltage. However, the proposed controller is able to distinguish and track the global maximum point of power under uniform and nonuniform ambient meteorological conditions.

Fig. 9 (c) shows the PV power curves of the proposed controller and the PSO-Backstepping controller. So, as this figure illustrates, the PSOBackstepping controller makes more iterations to find and track the global maximum points of power, which makes the system slow, while the proposed controller can scan and track rapidly the GMPP without any oscillation around this maximum.

Fig. 11 illustrates the grid current as well as the grid voltage. As can be illustrated, the current has the same phase and shape as the grid voltage, which means that the unity power factor is ensured.

As can be seen in Fig. 12, the grid current tracks rapidly and accurately the reference signal, which proves the aptitude and tracking performances of the sliding mode controller to pursue any reference trajectory. Fig. 13 depicts the DC bus voltage and the desired voltage reference, it is noted that the DC bus voltage pursues the reference of voltage, and makes a small overtaking during the meteorological conditions change.

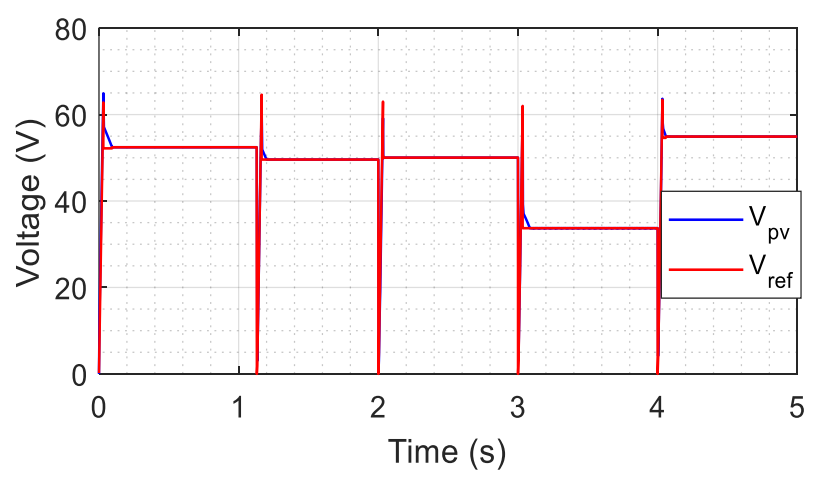

Figure.8 Voltage at the terminals of the PV panel 


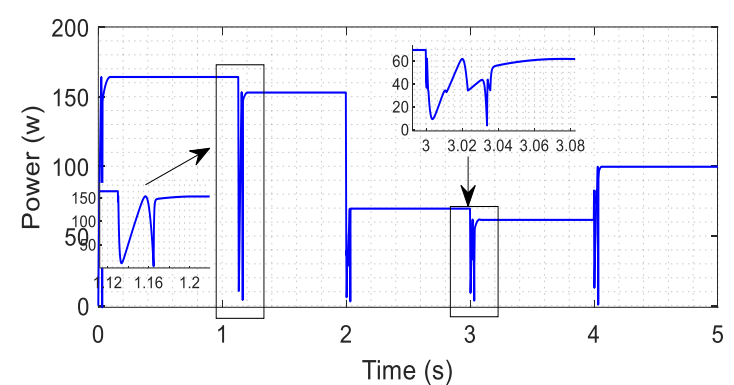

(a)

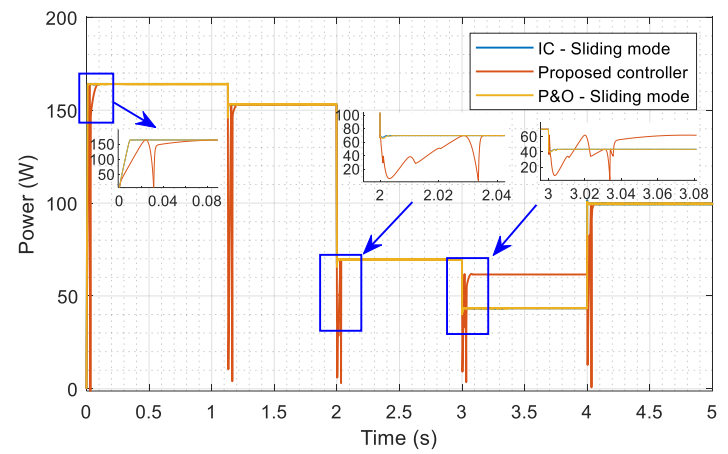

(b)

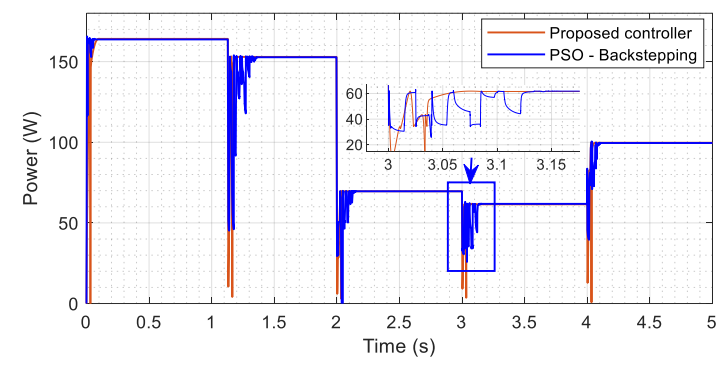

(c)

Figure.9 Power at the terminals of the PV panel

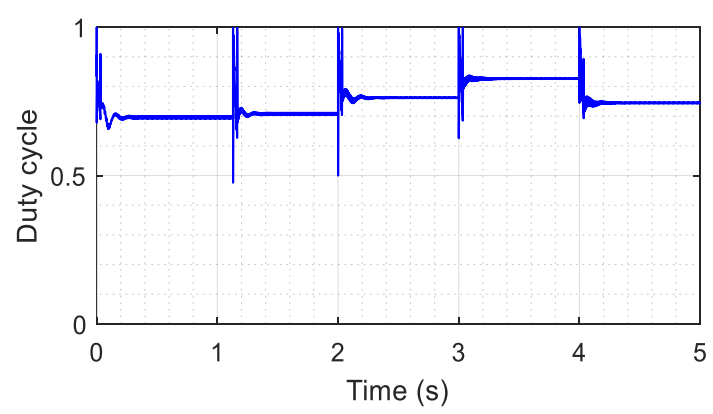

Figure.10 Input control of the SEPIC converter

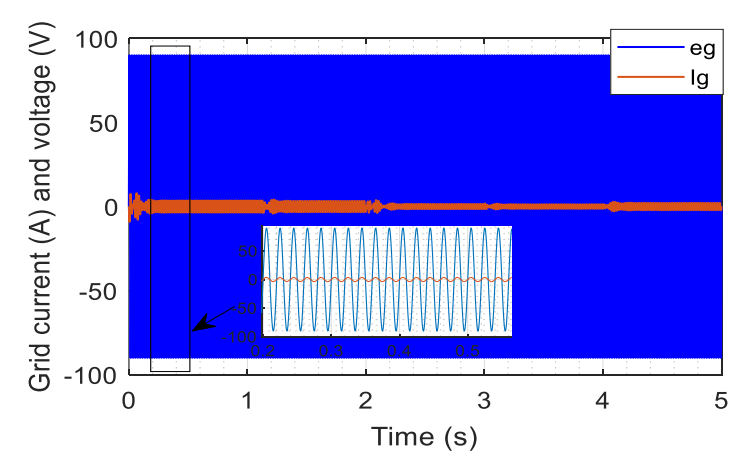

Figure.11 Grid current and voltage

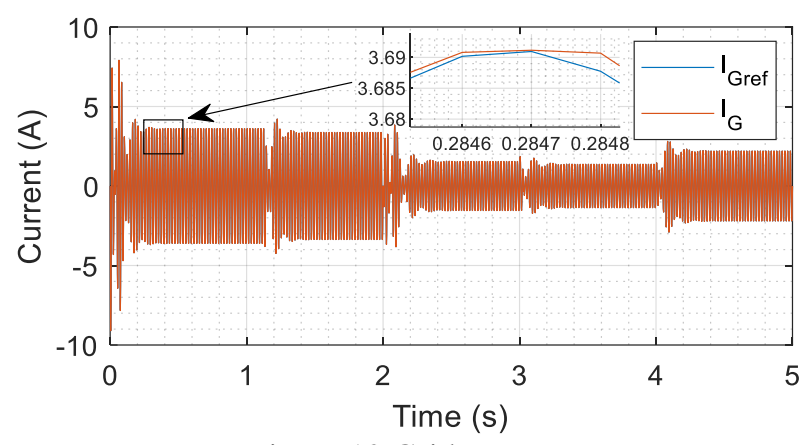

Figure.12 Grid current

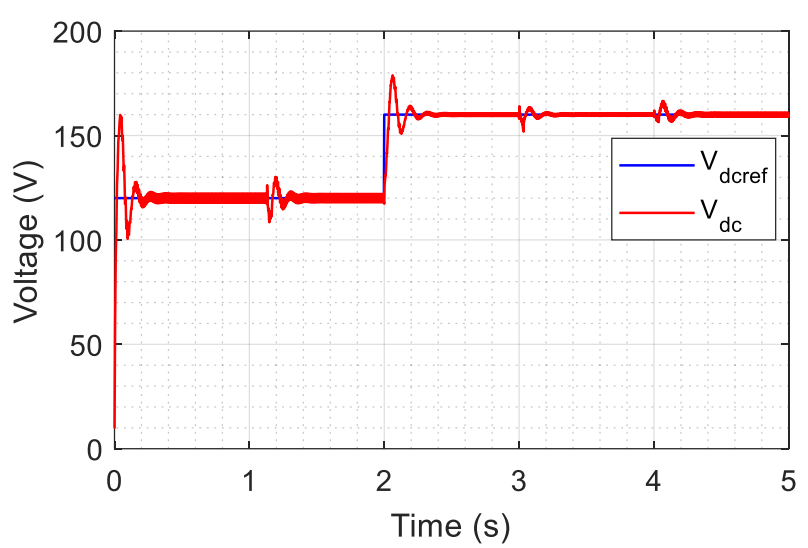

Figure.13 DC bus voltage

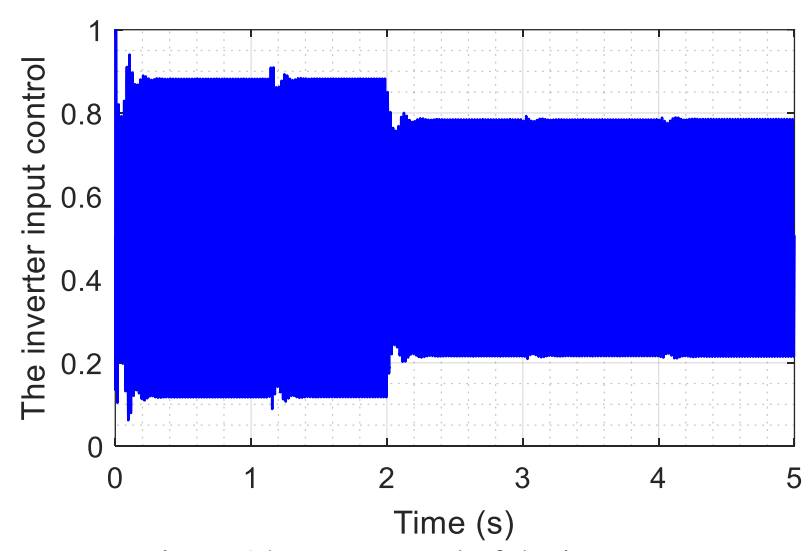

Figure.14 Input control of the inverter

The input control of the inverter is shown in Fig. 14. Fig. 15 shows the estimated DC bus voltage $\left(V_{d c}\right)$, the estimated voltage at the terminals of capacitor $C_{I}$ $\left(V_{C I}\right)$ and the estimated grid current $I_{G}$. While Fig. 16 shows the errors between the estimated and the actual states. Effectively, as can be seen, these errors are very small, which means that the high-gain observer can work properly. Therefore, it can be used instead of the current and voltages sensors.

The regulators' parameters, as well as the parameters of the high-gain observer and the PV system, are given in Table. 2 . 


\section{Conclusion}

An improved controller is proposed in this study. This one consists of the sliding mode controller and an algorithm called SLG.

On the one hand, the proposed controller is compared with the hybrid MPPT controllers such as the P\&OSMC and IC-SMC controllers. Results have shown that these controllers are not able to track the GMPP under the partial shading effect, while the proposed controller can distinguish the GMPP under uniform and non-uniform meteorological conditions.

On the other hand, the proposed controller is compared with the most known algorithm which is the PSO combined with the Backstepping controller. Results have illustrated that this controller can track the GMPP, however this one takes more tracking time. While the proposed controller can track the GMPP in 40ms. Effectively, this time depends on the shading pattern.

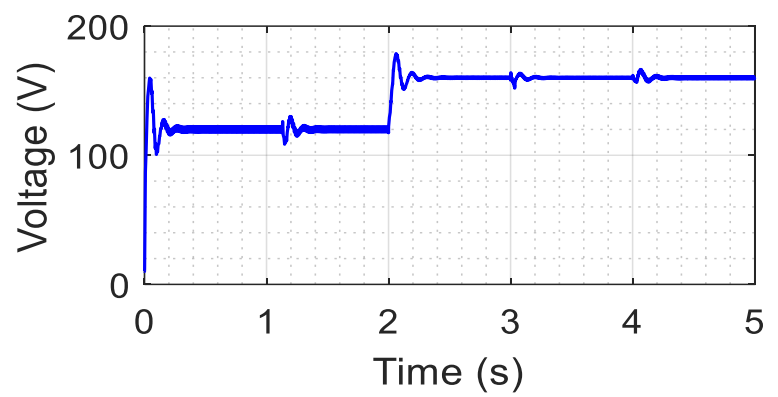

(a)

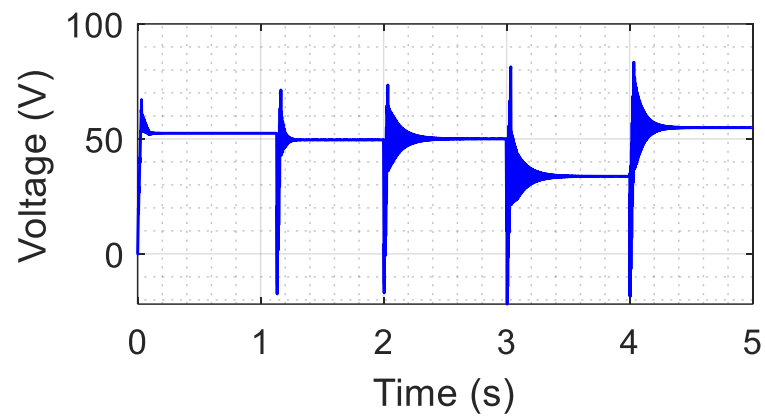

(b)

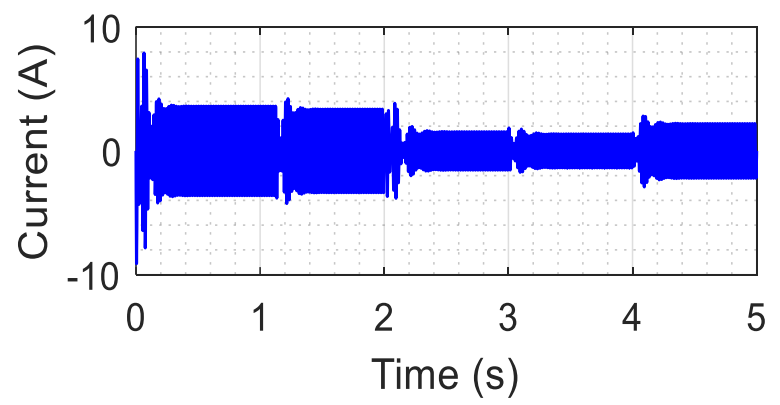

(c)

Figure.15 Estimated: (a) $V_{d c}$, (b), $V_{C l}$ and (C) $I_{G}$

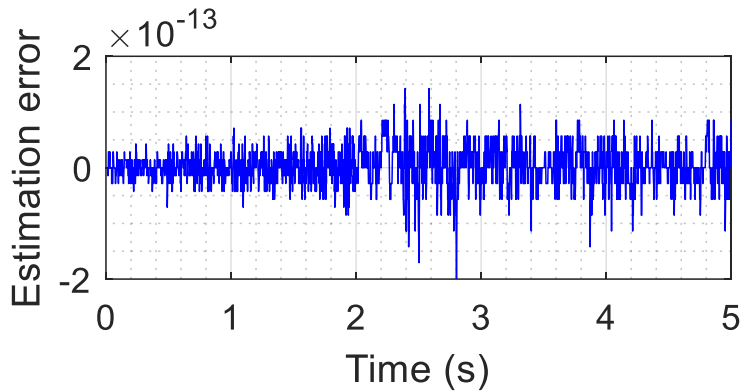

(a)

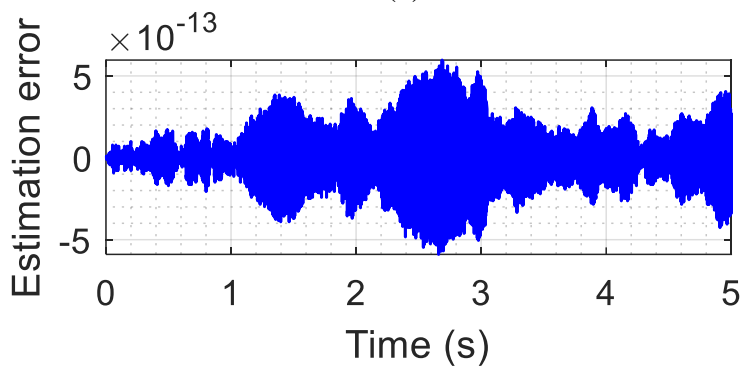

(b)

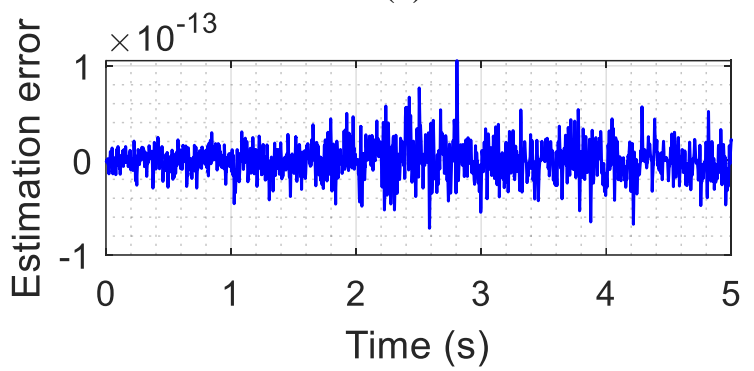

(c)

Figure.16 Estimation errors of: (a) $V_{d c}$ (b) $V_{C l}$ and (C) $I_{G}$

Table 2. Regulators and PV system parameters

\begin{tabular}{|l|l|}
\hline \multicolumn{1}{|c|}{$\begin{array}{c}\text { SEPIC and grid } \\
\text { parameters }\end{array}$} & \multicolumn{1}{c|}{$\begin{array}{c}\text { Proposed regulators' } \\
\text { parameters }\end{array}$} \\
\hline$C_{p v}=440 \mu \mathrm{F}$ & $K_{1}=9 \times 10^{4}$ \\
\hline$C_{1}=100 \mu \mathrm{F}$ & $\lambda_{1}=1000$ \\
\hline$L_{1}=1 \mathrm{mH}$ & $\Delta P=0.1 \mathrm{~W}$ \\
\hline$C_{d c}=1000 \mu \mathrm{F}$ & $\Delta V=0.1 \mathrm{~V}$ \\
\hline$L_{2}=1 \mathrm{mH}$ & $K_{2}=210$ \\
\hline$L_{G}=2.2 \mathrm{mH}$ & $K_{p}=0.001$ \\
\hline$R_{G}=0.47 \Omega$ & $K_{i}=0.1$ \\
\hline$e_{G \max }=90 \mathrm{~V}$ & $\theta=2$ \\
\hline$f=50 \mathrm{~Hz}$ & \\
\hline
\end{tabular}

On the other hand, this controller is combined with the high-gain observer in order to minimize number of sensors required. The PV system is then connected to the grid. The sliding mode controller is designed and used again to provide the unity power factor. While the DC bus voltage is regulated using the PI controller. The results have illustrated that the connection to the grid is ensured, and the sinusoidal current, with the same shape and phase as the voltage grid, is injected. The high-gain observer is used also to replace the grid current sensor. The high-gain 
observer has shown its ability to properly replace some sensors of current and voltages.

The proposed controller will be implemented in the external card in order to validate in the real time its aptitude to track the GMPP under changed meteorological conditions.

\section{References}

[1] M. Mokhlis, M. Ferfra, A. Abbou, and R. El idrissi, "Robust Control for Photovoltaic System Under Partial Shading Effect Using the SEPIC Converter", International Journal of Renewable Energy Research, Vol.9, No.2, 2019.

[2] R. El Idrissi, A. Abbou, M. Mohcine, and M. Salimi, "A comparative study of MPPT controllers for photovoltaic pumping system", In: Proc. of International Renewable Energy Congress, pp.1-6, 2018.

[3] A. Cheikhne Cheikh, M. Cherkaoui, and M. Mokhlis, "MPPT Control for Photovoltaic System using hybrid method under variant weather condition", In: Proc. of Wireless Technologies, Embedded and Intelligent Systems, pp.1-5, 2019.

[4] S. Thakran, J. Singh, R. Garg, and P. Mahajan, "Implementation of P\&O Algorithm for MPPT in SPV System", In: Proc. of International Conf. on Power Energy, Environment and Intelligent Control, pp.242-245, 2018.

[5] T. Halder, "A maximum power point tracker (MPPT) using the incremental conductance (INC) technique", In: Proc. Of India International Conf. on Power Electronics, pp.16, 2016.

[6] A. Mohapatra, D. Reddy, and S. Ramasamy, "A fuzzy logic MPPT controller based three phase grid-tied solar PV system with improved CPI voltage", In: Proc. of Innovations in Power and Advanced Computing Technologies, pp. 1-6, 2017.

[7] A. Mohapatra, B. Nayak, and C. Saiprakash, "Adaptive Perturb \& Observe MPPT for PV System with Experimental Validation", In: Proc. of IEEE International Conf. on Sustainable Energy Technologies and Systems, pp. 257-261, 2019.

[8] R. El Idrissi, A. Abbou, S. Rhaili, and M. Salimi, "Maximum power point tracking of photovoltaic systems using backstepping controller", In: Proc. of International Conf. on Engineering and Technology, , pp.1-6, 2017.

[9] A. Taouni, A. Abbou, M. Akherraz, A. Ouchatti, and R. Majdoul, "MPPT design for photovoltaic system using backstepping control with boost converter", In: Proc. of International Renewable and Sustainable Energy Conf., pp.469-475, 2016.

[10] S. Marhraoui, A. Abbou, A. Ziouh, N. El Hichami, and S. Rhaili, "Robust Integral Backstepping Approach for MPPT in Different Models of Solar Panel", In: Proc. of International Conf. on Renewable Energy Research and Applications, pp.371-376, 2018.

[11] L. Fei and Z. Jiandi, "The MPPT technology based on integral sliding mode control", In: Proc. of IEEE International Conf. on Information and Automation, pp. 288-292, 2017.

[12] M. Mokhlis and M. Ferfra, "Optimization of Photovoltaic Panels Efficiency Using a Backstepping Control Technique Under Partial Shading Conditions", International Review on Modelling and Simulations, Vol.10, No.6, pp. 437-446, 2017.

[13] M. Efendi, F. Murdianto, and R. Setiawan, "Modeling and simulation of MPPT sepie converter using modified PSO to overcome partial shading impact on DC microgrid system", In: Proc. of International Electronics Symposium on Engineering Technology and Applications, pp.27-32, 2017.

[14] J. A. Valderrama, M. Mantilla Villalobos, J. Barrero Pérez, J. Ptit Suàrez, and B. Ordonez Plata, "A Maximum Power Point Tracking Algorithm for Photovoltaic Systems under Partially Shaded Conditions", Ing. Univ., Vol.20, No.2, pp.391-409, 2016.

[15] M. Mokhlis, M. Ferfra, and M. Chraygane, "Nonlinear Control of a Photovoltaic Pumping System under Partial Shading", In: Proc. of International Renewable and Sustainable Energy Conf., pp.1-7, 2017. 